\title{
Investigation of Monovalent and Bivalent Enantioselective Molecular Recognition by Electrospray Ionization-Mass Spectrometry and Tandem Mass Spectrometry
}

\author{
Kevin A. Schug, ${ }^{a}$ Manishkumar D. Joshi, ${ }^{a}$ Petr Fryčák, ${ }^{\text {a,* }}$ \\ Norbert M. Maier, ${ }^{b,+}$ and Wolfgang Lindner ${ }^{b}$ \\ ${ }^{a}$ Department of Chemistry and Biochemistry, The University of Texas at Arlington, Arlington, Texas, USA \\ ${ }^{b}$ Department of Analytical Chemistry and Food Chemistry, University of Vienna, Vienna, Austria
}

In@his@vork@s@escribed@he@investigation@f@ivalent@ersus@monovalent@enantioselective molecular@ecognition@n@he@ontext@f@nantioselective@eparations.@ilectrospray@onizationmass@pectrometryథESI-MS)@ndథandem@nass@pectrometryథMS/MS)@re@sedథror@valuating enantioselective@systems@through@the@measurement@of@(1)@relative@solution-phase@binding constants@ia@itration@nd@2)@elative@as-phase@inding@ia@ollision@hreshold बissociation.@n HPLC,@inchonane-type@hiral@tationary@hase@CSP)\$ased@nథert.-butylcarbamoylquinine provides@astly@ncreased@etention@and@nantioselectivity@or@eparation@f@ivalent@ersus monovalent@lkoxy-benzoyl-N-blockedథeucine@nantiomers. to@pan@nd@imultaneously@nteract@ith@nultiple@interaction@ites@n@he@SP@urface, $\$$ (teading to@nhanced@eparation.@SI-MS@itration@measurements@lso@how@n@ncreased@vidity@or binding@between@bivalent@elector@and@ivalent@electand,@ompared@with@the@monovalent system.đHowever,@nhanced@nantioselectivities@neasured@n@HPLC@or@he@ivalent@ystem

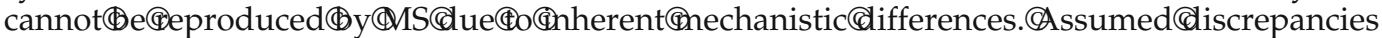
in@elative@esponse@actors@lso@ive@ise@o@ystematic@rrors@hich@re@iscussed.@he@esults

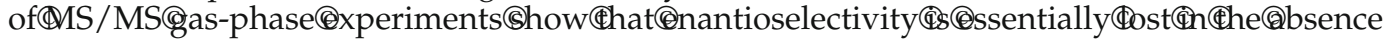
of@olvation,@ut@hat@issociation@hresholds@an@rovide@@measure@f@elative@issociation

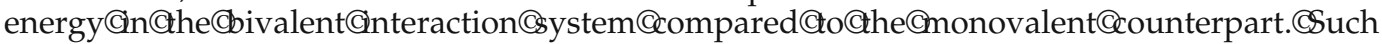
measurements@nay@rove@iseful@nd@fficient@n@better@inderstanding@multivalent@nteractions,@n@ine@vith@urrent@heoretical@onsiderations@f@ffective@oncentrations@nd@on@rap effects.CThis@s@heđirst@pplication@f@mass@pectrometric@methods@or@ssessing@increased avidity@f@inding@n@multivalent@nantioselective@molecular@ecognition.@ (J@Am@Soc@Mass Spectrom(2008,@9,@629@1642)@(2008@American@society@or@Mass@Pectrometry

$\mathrm{M}$ ultivalent@molecular@recognition@refers@to@a process@here@oncovalent@ssociation@s@nduced@y@@eceptor,@hich@mploys@ultiple copies@f@n@dentical@unctional@nitథoథind@o@థigand with@similarly@arranged@copies@of@a@complementary

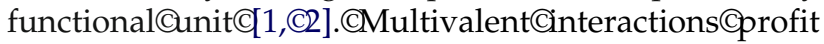
from@n@enhancement@n@avorable@nthalpic@ontributions@o@inding@ue@o@nultiple@ontact@ites@n@ndividual@nolecules,@while@infavorable@ntropic@osts@ssociated@ith@he@indingథrocess@re@imilar@o@hat@or the@monovalent@ystem.@n@ther@words, @he@ntropic penalty@for@binding $₫$ disruption@of@olvent@molecules

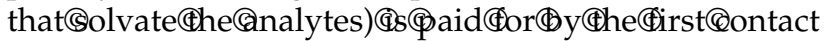

\footnotetext{
Address reprint requests to Dr. K. A. Schug, Department of Chemistry and Biochemistry, The University of Texas at Arlington, 700 Planetarium Pl., Campus@Box@19065,(Arlington,CTX@76019-0065,CUSA.CE-mail:@kschug@ uta.edu

* Current address: Department of Molecular Biology and Immunology, The University of North Texas Health Science Center, Fort Worth, TX.

+ Current address: Chiral Technologies, Inc., Westchester, PA.
}

of@omplementary@receptor-ligand@unctional@units@t one@site,Cbringing@other@interaction@sites@into@close proximity,@nd@esulting@n@increased@ffinity.৫Huskens et@1.@have@rovided@@etailed@reatment@f@he@hermodynamics@f@nultivalent@nteractions@t@olutionsurfaceđinterfaces@[3].CThis@model@requires@the@explicit consideration@fCுeffective@oncentrations,"@which@re defined@by@the@characteristics@of@the@surface-bound receptors@(display, Corientation, @flexibility, Carrangements,@moothness@f@urface,@elative@pacing@f@electors@rom@each@other, @etc.)@and@he@properties@of@he multivalent@nalytes@nature@f@inkers, $₫$ lexibility,@otational@reedom, (humber@f@interaction@ite@notifs@incorporated).đn@impler@erms, (he@penomena@nd@ssociated nomenclature for multivalent interactions are shown in Figure 1.

The scientific literature is rich with examples where multivalent synthetic receptors and ligands are employed to increase avidity. Whitesides and coworkers reported the synthesis of model bivalent and trivalent 


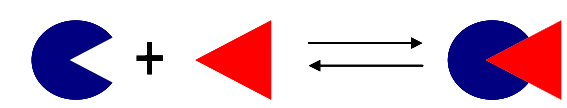

"Monovalent"
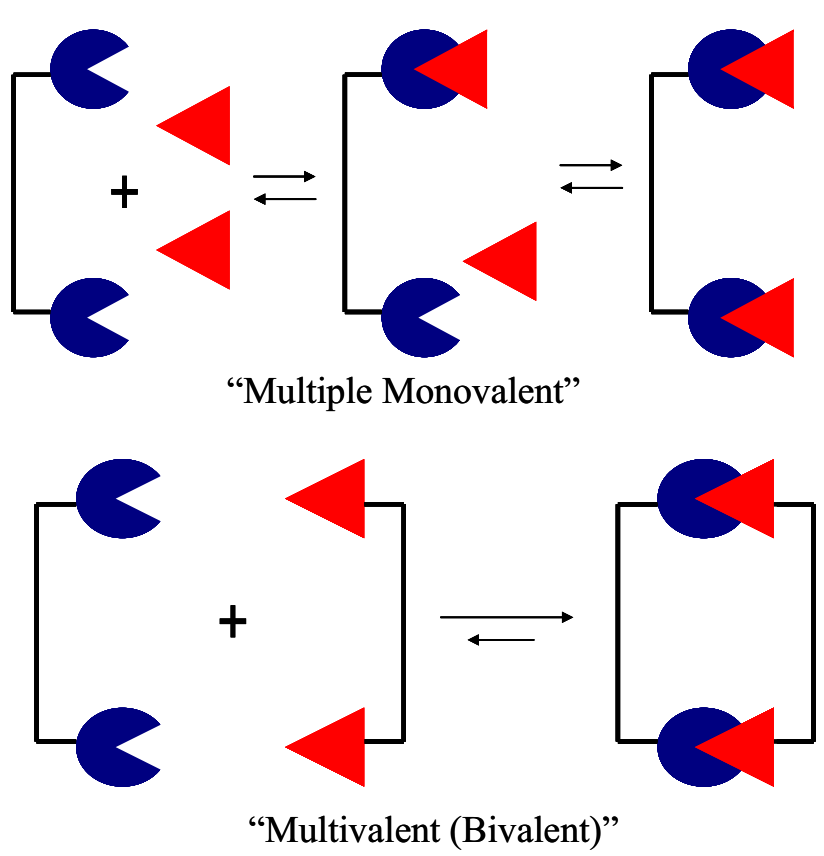

Figure 1. Schematic and nomenclature for monovalent and bivalent interaction systems.

vancomycin-bacterial cell wall tripeptide systems and their subsequent binding affinity determinations [4-6]. Whereas the monovalent vancomycin-Ac- $L$-Lys- $D$-Ala$D$-Ala interaction is characterized by a dissociation constant $\left(K_{\mathrm{d}}\right)$ of $\sim 10^{-6} \mathrm{M}[7,8]$, the bivalent and trivalent arrangements (both the receptor and the ligand were each synthesized to properly orient multiple functional units with appropriate spacers) returned enhanced binding affinities, giving $K_{\mathrm{d}}=10^{-9}$ and $10^{-17}$ $\mathrm{M}$, respectively. Breslow and Zhang reported cholesterol recognition using a synthesized $\beta$-cyclodextrin $(\mathrm{CD})$ dimer, where the bivalent receptor $\left(K_{\mathrm{d}}=1.8 \times\right.$ $\left.10^{-7} \mathrm{M}\right)$ showed a 300-fold enhancement in binding, relative to monovalent $\beta$-CD $\left(K_{\mathrm{d}}=5.9 \times 10^{-5} \mathrm{M}\right)$ [9]. Stoddart and coworkers have spent considerable effort studying the binding of multivalent ammonium cation arrangements with multivalent crown ether-based receptors, showing substantial increases in affinity relative to monovalent counterparts [10-12]. Related work has included collaborative efforts to incorporate multivalency into the design of nanomachines such as molecular elevators [13]. Reinhoudt and coworkers have also made substantial contributions to the use and understanding of multivalency in nanofabrication processes $[2,3,14]$.

Researchers have invoked the model of multivalency and polyvalency to better understand and influence life processes in the biochemical arena [1,15]. Novel bivalent intercalating binders based on [ $n]$-polynorbornane have been developed to improve DNA recognition by
Waring and coworkers [16]. In a similar effort, Luger and coworkers designed hairpin polyamide dimers to target a nucleosomal supergroove on chromatin [17]. Hol and coworkers synthesized a series of bivalent ligands to study their ability to inhibit the activity of cholera toxin, returning significant potency gains [18]. Others have used a phage display optimization approach to reveal bivalent ligands based on proline-rich peptide segments to recognize and inhibit $\mathrm{SH} 3$ domains involved in diverse signaling pathways [19]. Also, homo- and heterobivalent inhibitors based on aldehyde peptide head groups have been reported for enhanced inhibition of proteosome, a multicatalytic protease [20]. Taken together, these works represent only a fraction of the studies demonstrating the effects of multivalent molecular recognition architectures in biochemical systems.

In the field of separation science, one of the most challenging tasks is the separation of enantiomers [21]. New "chiral selectors" (receptors capable of enantioselective discrimination) are constantly in demand to meet the challenges of separating and purifying new chiral entities produced by pharmaceutical and agrochemical industries. Chiral selectors achieve enantioselectivity by displaying a chiral scaffold that can differentially bind one enantiomer over another. In most cases, chiral selectors are highly specialized in the types of enantiomers they can effectively discriminate. Minute differences in binding affinity must often be optimized to achieve resolution of the desired target enantiomers. It would thus seem reasonable to invoke the multivalency concept as a means to amplify enantioselectivity provided by monovalent systems where resolution is less than acceptable.

Pirkle and coworkers demonstrated this advantage when they studied the inter-functional distance between enantioselective recognition motifs on a chiral stationary phase (CSP) using synthesized bivalent analyte stereoisomers [22, 23]. Bis(amide) linked 3,5dinitrobenzoyl-leucine (DNB-Leu) enantiomers, incorporating a homologous series of spacer units, were chromatographed on $\mathrm{N}$-(2-naphthyl)alanine-derived CSPs. Selectivities $(\alpha)$ were compared with separation, on the same CSP, of monovalent DNB-Leu enantiomers. For the optimum case, the $n$-hexyl bis(amide) of DNBLeu was separated with $\alpha=121$, a substantial increase over that obtained for monovalent DNB-Leu $(\alpha=10.5)$. The bivalent ligand displayed appropriate spacing for simultaneous enantioselective interaction with two complementary bound stationary phase units to achieve an approximate doubling of $\Delta \Delta \mathrm{G}$ for enantiodiscrimination. More recently, Ling et al. investigated the beneficial effects of multivalency when they described the preparation of dendritic CSPs based on L-proline indananilide chiral selectors on polymeric beads [24]. Enantioselectivities up to $\alpha=31$ were recorded for a series of $\mathrm{N}$-dinitrobenzoylated amino acids. In general, the enhancements provided by these multivalent enantioselective systems are impressive, providing an additional experimental and theoretical 
<smiles>C=CC1CN2CCC1C[C@@H]2C(OC(=O)NC(C)(C)C)c1ccnc2ccc(OC)cc12</smiles>

1

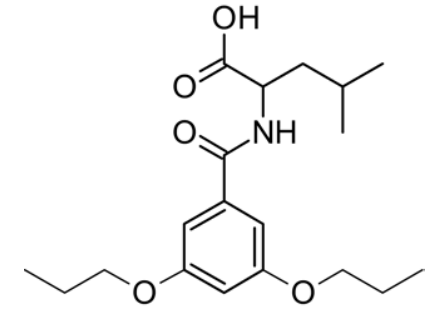

3 basis for studying the resultant increase in avidity. However, the general applicability of such approaches is limited because of the time-consuming nature associated with preparing bivalent ligands from their monovalent counterparts before separation. For purification purposes, the bivalent ligands would need to be decoupled following separation.

Despite apparent limitations in practical implementation, the concept of enantioselective multivalent recognition fits well within the efforts of ongoing research in our group to develop and evaluate mass spectrometric methods for measuring binding affinities in small molecule molecular recognition systems [25-28]. The investigation of molecular recognition and noncovalent binding systems by both solution-phase- and gasphase-based mass spectrometric methods is a growing area of research over the last decade [27-36]. The cited review articles indicate a wealth of applications in the areas of protein (enzyme)-ligand and oligonucleotide (RNA, DNA)-ligand interaction systems. With respect to small molecule [37-44] and chiral recognition systems [25, 26, 28, 45-48], far fewer quantitative solutionphase affinity studies have been reported utilizing ESI-MS. The majority of work relating the application of mass spectrometry to studying enantioselective interactions has centered on gas-phase tandem mass spectrometric (e.g., by ion/molecule reactions and the kinetic method) or desorption mass spectrometric (e.g., by fast atom bombardment) experiments [49-58]. Although many of these approaches are applicable for analysis of enantiomeric excess, given suitable calibration, the nature of the experiments provides less information about mechanisms associated with enantioselective interactions in the solution phase. On a related note, previous examples of the study of multivalent binding by mass spectrometry include work by Klassen and coworkers [59] on the binding between Shiga-like toxin with

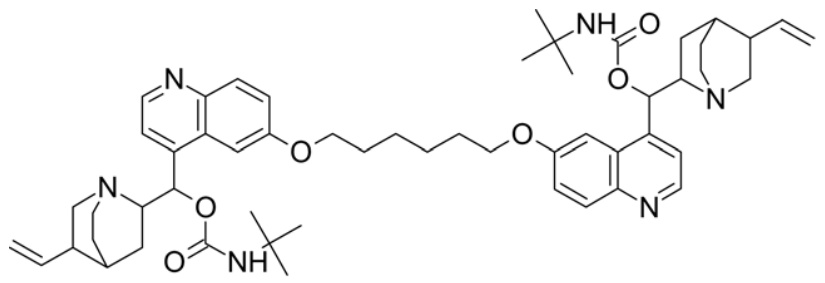

globotriaoside, and by Meijer and coworkers [60] on the collisional dissociation of multiple monovalent dendrimeric binding interactions in the gas phase.

In this work is described the application of electrospray ionization-mass spectrometry (ESI-MS)-based titration measurements and collision activated dissociation threshold tandem mass spectrometry measurements to study multivalent enantioselective molecular recognition. Our model system is composed of monovalent (1) and bivalent (2) forms of the cinchonane-type chiral selector, tert-butylcarbamoylquinine [tBuCQN; $(8 S, 9 R)]$, binding the enantiomers of mono- (3) and bis- $N$-alkoxybenzoylated leucine (4). Solution-phase-targeting mass spectrometric-based titration experiments using 1:1 and 1:2 binding models are employed to compare monovalent, multiple monovalent, and bivalent interaction strengths. Gas-phase collision threshold measurements are performed to study binding in the gas-phase for the bivalent compared to the monovalent systems in the absence of solvation. Enantioselectivities obtained by ESI-MS measurements are compared with HPLC separations of 3 and 4 on a cinchonane-type CSP (based on tBuCQN 1).

A clear distinction should be noted concerning the experimental approaches employed in this investigation. In HPLC separations, multiple association and dissociation events give rise to a series of step-by-step solid-liquid equilibria (multiple theoretical plates) characterized by the guest binding to a surface presenting multiple host receptor sites. A selectivity value is cal-

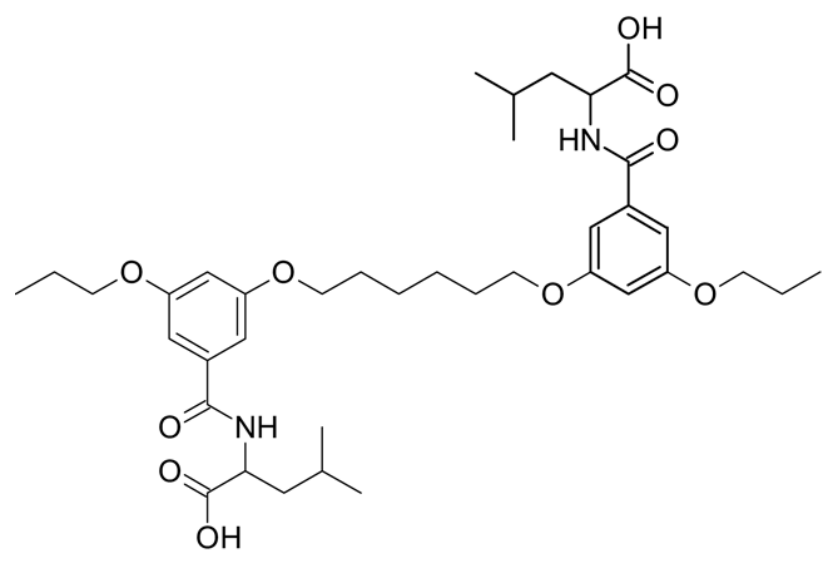


culated as a ratio of HPLC retention factors. In the mass spectrometry experiment, selectivity is represented as a ratio of dissociation constant values taken from the measurement of a single equilibrium in solution (one theoretical plate). However, the underlying equilibria in both cases are essentially the same with the exception of HPLC retention effects arising from the bonding chemistry (tether) used to create the CSP. The goal of this work is to evaluate ESI-MS and MS/MS techniques [27, 29 , 32] for probing the increased avidity (relative interaction energies) and enantioselectivity (configurational preference) offered by bivalent compared with monovalent recognition systems in the solution phase, and compared to HPLC separation processes. Mass spectrometry may not be an ideal choice for probing surface-based interactions, but it is the only tool that allows direct observation of all relevant species in the multivalent equilibria.

Prior results in this research area published by our group have shown that the absolute affinity of enantioselective binding interactions measured by ESI-MS titrations can be shifted to higher affinity compared with those values obtained by more traditional solutionphase techniques, leading inevitably to poor accuracy, despite excellent precision, for absolute binding constant determinations in these small molecule systems [25-27]. However, the relative binding affinities (ratio of binding constants), indicative of the sought enantioselective performance of new cinchona alkaloid-based recognition systems, match very well those relative values obtained by complementary solution-phase methods (e.g., by microcalorimetry) and HPLC separations on a CSP. The data and results presented here provide complementary information for the investigation of multivalent interactions and are presented with a critical discussion of the merits and limitations of the mass spectrometric experiments. This is the first time measurements of relative binding affinities for multivalent enantioselective recognition systems, based on ESI-MS titration and collision threshold dissociation methods and in the context of evaluating the performance of potential chiral separation media, have been reported.

\section{Experimental}

\section{Chemicals and Synthesis}

LC-MS grade water $\left(\mathrm{H}_{2} \mathrm{O}\right)$ and HPLC grade methanol $(\mathrm{MeOH})$ from J. T. Baker (Phillipsburg, NJ) composed the bulk of the sample solutions prepared for mass spectrometry analysis. Sodium acetate (NaOAc) (EMD Chemicals, Gibbstown, NJ) and ammonium acetate $\left(\mathrm{NH}_{4} \mathrm{OAc}\right)$ (J. T. Baker) were used as solution-phase modifiers. All samples were prepared in 50:50 (vol/vol) $\mathrm{MeOH} / \mathrm{H}_{2} \mathrm{O}$ with $100 \mu \mathrm{M} \mathrm{NH}_{4} \mathrm{OAc}$ and $10 \mu \mathrm{M}$ NaOAc. This composition was chosen to mimic solution-phase conditions employed for enantioselective ion-exchange separation of $N$-block amino acid enantiomers on cinchonane-type CSPs by HPLC $[61,62]$. It is also consistent with previously published work related to ESI-MS binding affinity studies using cinchona alkaloid host systems [25, 26].

The enantiomerically-pure chiral selector (host) and chiral selectand (guest) monovalent and bivalent systems investigated in this work were synthesized at the Institute for Analytical Chemistry and Food Chemistry at the University of Vienna. Monovalent selector 1 was prepared following a procedure described previously [63]. Bivalent selector 2 was synthesized from quinine in six steps in $31 \%$ overall yield. Monovalent and bivalent analytes 3 and 4 were prepared from 3,5-dihydroxybenzoic acid in six and nine steps in $5 \%$ and $16 \%$ overall yields, respectively. A detailed description of the synthetic procedures will be provided in a subsequent paper specifically focusing in the chromatographic aspects of multivalent chiral recognition.

Bivalent Selector: 1,6-Bis-(O6'-[9O-tert.Butylcarbamoyl-Cupreine])-Hexane; 2

Colorless solid. ${ }^{1} \mathrm{H}$ NMR $\left(\mathrm{CDCl}_{3}\right) \delta: 8.80(\mathrm{~d}, 2 \mathrm{H}), 7.47(\mathrm{~s}$, 2H), $7.35(\mathrm{~m}, 4 \mathrm{H}) 6.43(\mathrm{~d}, 2 \mathrm{H}), 5.85(\mathrm{~m}, 2 \mathrm{H}), 4.99(\mathrm{~m}, 4 \mathrm{H})$, $4.72(\mathrm{~s}, 2 \mathrm{H}) ; 4.14(\mathrm{~m}, 4 \mathrm{H}) ; 3.31(\mathrm{~m}, 2 \mathrm{H}), 3.04(\mathrm{~m}, 4 \mathrm{H}) ; 2.62$ $(\mathrm{m}, 4 \mathrm{H}), 1.95-1.42$ (overlapped $\mathrm{m}$ 's, $18 \mathrm{H})$ and $1.28(\mathrm{~s}$, 18H). ${ }^{13} \mathrm{C} \mathrm{NMR}\left(\mathrm{CDCl}_{3}\right) \delta: 187.8,147.8,145.2,144.6$, 143.0, 132.0, 127.9, 122.5, 119.0, 114.8, 102.7, 72.9, 68.6, $59.5,57.0,51.0,42.8,40.3,29.6,29.3,28.2,28.3,26.5$, and 24.5 ppm. ATR-IR (solid): 3239, 2934, 1725, 1621, 1591, 1510, and $1459 \mathrm{~cm}^{-1}$. MS: $[\mathrm{M}+\mathrm{H}]^{+}$at $901.6 \mathrm{~m} / \mathrm{z} ;[\mathrm{M}+$ $2 \mathrm{H}]^{2+}$ at $451.3 \mathrm{~m} / \mathrm{z}$. Optical rotation: $[\alpha]_{546}=-18.1^{\circ}(\mathrm{c}=$ 1.0, $\mathrm{MeOH}, 25^{\circ} \mathrm{C}$ ).

Monovalent Analytes: (R)- and (S)-2-(3,5Dipropoxy-Benzylamino)-4-Methyl-Pentanoic Acid; (R)-3 and (S)-3

Colorless solid. ${ }^{1} \mathrm{H} \mathrm{NMR}\left(\mathrm{CDCl}_{3}\right) \delta: 10.33(\mathrm{~s}$, broad, $1 \mathrm{H})$, $6.89(\mathrm{~s}, 2 \mathrm{H}), 6.59(\mathrm{~s}, 1 \mathrm{H}), 6.51(\mathrm{~d}, 1 \mathrm{H}), 4.81(\mathrm{~m}, 1 \mathrm{H}), 3.93$ $(\mathrm{t}, 4 \mathrm{H}), 1.79(\mathrm{~m}, 6 \mathrm{H}), 1.69(\mathrm{~m}, 1 \mathrm{H}), 1.03(\mathrm{t}, 6 \mathrm{H})$ and 0.97 $(\mathrm{m}, 6 \mathrm{H}) .{ }^{13} \mathrm{C} \mathrm{NMR}\left(\mathrm{CDCl}_{3}\right) \delta: 177.4,168.1,160.8,136.0$, 105.9, 105.2, 70.3, 51.76, 41.7, 25.4, 23.3, 22.9, 22.3, and 10.9 ppm. ATR-IR (solid): 3928, 2965, 2879, 1707, 1634, 1592, 1533, and $1436 \mathrm{~cm}^{-1}$. MS: $[\mathrm{M}-\mathrm{H}]^{-}$at $350.2 \mathrm{~m} / \mathrm{z}$ for both enantiomers. Optical rotation: $(S)-3,[\alpha]_{546}=$ $-12.2^{\circ}\left(\mathrm{c}=1.0, \mathrm{MeOH}, 25^{\circ} \mathrm{C}\right) ;(R)-3,[\alpha]_{546}=+12.1^{\circ}(\mathrm{c}=$ 1.0, $\left.\mathrm{MeOH}, 25^{\circ} \mathrm{C}\right)$.

Bivalent Analytes: $\left(2 R, 2^{\prime} R\right)-$ and $\left(2 S, 2^{\prime} S\right)-2-(3-$ \{6-[3-((2R')-1-Carboxy-3-Methyl-Butylcarbamoyl)5-Propoxy-Pehnoxy]Hexyloxy\}-5-PropoxyBenzylamino)-4-Methyl-Pentanoic Acid; $\left(2 R, 2 R^{\prime}\right)-4$ and $\left(2 S, 2 S^{\prime}\right)-4$

Colorless solid. ${ }^{1} \mathrm{H} \mathrm{NMR}\left(\mathrm{CDCl}_{3}\right) \delta: 10.06$ (s, broad, $\left.2 \mathrm{H}\right)$, $6.89(\mathrm{~s}, 2 \mathrm{H}), 6.87(\mathrm{~s}, 2 \mathrm{H}) 6.64(\mathrm{~s}, 1 \mathrm{H}), 6.62(\mathrm{~s}, 1 \mathrm{H}), 4.81(\mathrm{~m}$, $2 \mathrm{H}), 3.97(\mathrm{t}, 4 \mathrm{H}) ; 3.90(\mathrm{t}, 4 \mathrm{H}) ; 1.78(\mathrm{~m}, 10 \mathrm{H}), 1.67(\mathrm{~m}, 2 \mathrm{H})$; 
$1.52(\mathrm{~m}, 4 \mathrm{H}), 1.03(\mathrm{t}, 6 \mathrm{H})$, and $0.97(\mathrm{~m}, 12 \mathrm{H}) .{ }^{13} \mathrm{C} \mathrm{NMR}$ $\left(\mathrm{CDCl}_{3}\right) \delta: 177.5,168.4,160.8,160.71,136.1,106.08,70.25$, 68.50, 51.76, 14.57, 29.40, 26.15, 25.39, 23.27, 22.89, 22.30, and 10.87 ppm. ATR-IR (solid): 3306, 2935, 2864, 1717, $1640,1593,1526$, and $1454 \mathrm{~cm}^{-1}$. MS: $[\mathrm{M}-\mathrm{H}]^{-}$at 699.4 $\mathrm{m} / \mathrm{z} ;[\mathrm{M}-2 \mathrm{H}]^{2-}$ at $349.2 \mathrm{~m} / \mathrm{z} ;[\mathrm{M}-2 \mathrm{H}+\mathrm{Na}]^{-}$at 721.4 $\mathrm{m} / \mathrm{z}$ for both enantiomers. Optical rotation: $\left(2 S, 2 S^{\prime}\right)-4$ enantiomer: $[\alpha]_{546}=-11.2^{\circ}\left(\mathrm{c}=1.0, \mathrm{MeOH}, 25^{\circ} \mathrm{C}\right)$; $\left(2 R, 2 R^{\prime}\right)-4:[\alpha]_{546}=+11.3^{\circ}\left(\mathrm{c}=1.0, \mathrm{MeOH}, 25^{\circ} \mathrm{C}\right)$.

\section{Instrumental Analysis}

All mass spectrometric-based titration and collision threshold dissociation measurements were performed using a Surveyor HPLC system (pump and autosampler) hyphenated to a LCQ Deca XP quadrupole ion trap mass spectrometer with an in-built syringe pump manufactured by Thermo-Fisher Scientific, Inc. (West Palm Beach, FL). Source parameters were optimized for the observation of relevant "host-guest" (receptorligand, selector-selectand, etc.) complexes for monovalent, multiple monovalent, and bivalent interaction systems in the positive ionization mode using a conventional electrospray ionization source. In all cases, a spray capillary voltage of $5 \mathrm{kV}$ was applied using a coaxial sheath gas $\left(\mathrm{N}_{2}\right)$ flow rate of 20 arbitrary units. The transfer capillary temperature was set to $200{ }^{\circ} \mathrm{C}$ and the tube lens offset voltage was set to $20 \mathrm{~V}$. Variation of the latter parameter was assessed over a wide range to check its influence on the observed ionic complexes (data not shown). It was found that the intensity of the complex ions do not vary substantially over a reasonable range of tube lens offset voltages, indicating that temporal variations in this instrumental setting should not appreciably affect the transfer of the species of interest to the mass analyzer. For the monovalent system (binding between $\mathbf{1}$ and $\mathbf{3}$ ), the pump flow rate was set to $15 \mu \mathrm{L} / \mathrm{min}$, providing identical analysis conditions to those employed in previous experiments [26]. In the case of the multiple monovalent (binding between 2 and 3) and the bivalent (binding between 2 and 4) interaction systems, a flow rate of $50 \mu \mathrm{L} / \mathrm{min}$ was employed due to the better signal quality observed under this setting.

For titration experiments, discrete sets of $1 \mathrm{~mL}$ sample solutions in $50 / 50 \mathrm{MeOH} / \mathrm{H}_{2} \mathrm{O}$ were prepared containing the host molecule ( 1 or 2 ) at a constant concentration $(10 \mu \mathrm{M}$ for monovalent 1 and $5 \mu \mathrm{M}$ for multiple monovalent and bivalent 2 systems) and the guest molecule (3 or 4 ) in a range of concentration spanning at least two orders of magnitude (0.1 to 100 $\mu \mathrm{M}$, typically). The samples were introduced by an autosampler using the above-specified pump flow rate for each system, so that a plateau signal lasting $2 \mathrm{~min}$ for each sample injection was obtained. Each data point for the titration was measured in triplicate to obtain mass spectra, which were represented by an average of 50 scans, where each scan was a composite of 3 microscans. A suitable flushing step was incorporated between each triplicate sample measurement to reduce potential carry-over effects. Each complete titration was repeated three times with fresh solutions.

For collision threshold experiments [64-66], single sample solutions containing $10 \mu \mathrm{M}$ each of host and guest, along with $100 \mu \mathrm{M} \mathrm{NH}{ }_{4} \mathrm{OAc}$ and $10 \mu \mathrm{M} \mathrm{NaOAc}$ in $50 / 50 \mathrm{H}_{2} \mathrm{O} / \mathrm{MeOH}$, were introduced into the electrospray source on the LCQ Deca XP via an integrated syringe pump at $15 \mu \mathrm{L} / \mathrm{min}$. The observed 1:1 hostguest complex was isolated in the ion trap and subjected to collision activated dissociation (CAD). The collision activation voltage was varied from $0 \%$ to $75 \%$ (where $100 \%$ represents $5 \mathrm{~V}$ applied potential according to manufacturer specifications), and the loss of precursor ion signal was monitored relative to the appearance of other components observed in the MS/MS spectra. A constant q-value of 0.250 and an activation time of 30 ms were employed for all measurements. The software setting for collision energy normalization was turned off. At least 30 scans were averaged to obtain each data point, and each measurement was performed in triplicate.

The chromatographic measurements were carried out using a Merck Hitachi LaChrom HPLC system (Darmstadt, Germany), consisting of an L-7159 pumping system, and L-7250 programmable autosampler, an L-7455 diode array detector, and a D-7000 data interface. Data acquisition and manipulation was achieved using the Merck Hitachi HPLC system manager software (ver. 4.0), installed on a personal computer. Column temperature was maintained at $25^{\circ} \mathrm{C}(298 \mathrm{~K})$ by immersion into an electronically-controlled thermostatted water bath (Haake C4, Kurlsuhe, Germany). All measurements were carried out on a commercial Chiralpak AX-QN CSP $(150 \times$ $4.6 \mathrm{~mm}$ i.d., Chiral Technologies Europe, Illkirch, France) comprising selector $\mathbf{1}$ covalently immobilized onto the surface of $5 \mu \mathrm{m}$ spherical silica particles. A mixture of $\mathrm{MeOH} / \mathrm{HOAc} / \mathrm{NH}_{4} \mathrm{OAc}$ 98:2:0.5 (vol/vol/ $\mathrm{wt}$ ) was employed as mobile phase, with all components being of HPLC grade quality (Merck, Darmstadt, Germany). A flow rate of $3.0 \mathrm{~mL} / \mathrm{min}$ was used. Peaks were detected at $254 \mathrm{~nm}$. Samples were prepared in mobile phase, and the injected sample volumes (total amounts) were $10 \mu \mathrm{L}(10 \mu \mathrm{g})$ for monomeric analyte 2 and $20 \mu \mathrm{L}(40 \mu \mathrm{g})$ for dimeric analyte 3 . The enantiomer elution order of the analytes 3 and 4 were confirmed by injection of enantiomerically enriched samples. Thiourea was used as a marker for the hold-up time $\left(t_{h u}\right)$ of the chromatographic system. The column void time $\left(t_{0}\right)$ used for the calculation of the chromatographic parameters of 3 and 4 was corrected for extra-column contributions $\left(t_{\text {exc }}\right)$ of the chromatographic system $\left(t_{0}=\right.$ $\left.t_{\text {hu }}-t_{\text {exc }}\right)$. The reported values for the retention factors $k_{i}$ $\left(\mathrm{k}_{\mathrm{i}}=\left(\mathrm{t}_{\mathrm{i}}-\mathrm{t}_{0}\right) / \mathrm{t}_{0}\right)$ and enantioselectivity $\left(\alpha_{\mathrm{ij}}=\mathrm{k}_{\mathrm{i}} / \mathrm{k}_{\mathrm{j}}\right.$ with $\mathrm{k}_{\mathrm{i}} / \mathrm{k}_{\mathrm{j}}>1$ ) are the mean values from three independent chromatographic measurements. 


\section{Titration Models}

To determine apparent dissociation constants based on the mass spectrometric data, a theoretical binding equilibrium model based on standard arguments (including an appropriate minimization procedure for fitting to the experimental data) was used to account for 1:1 binding in the monovalent and bivalent, and 1:2 binding in the multiple monovalent, interaction systems. For the latter case, interaction of bivalent host $(\mathrm{H})$ with monovalent guest $(G)$ consisted of two interconnected equilibria characterized by two dissociation constants $\left(K_{\mathrm{d} 1}, K_{\mathrm{d} 2}\right)$ :

$$
\begin{array}{lc}
H G \leftrightarrow H+G & K_{\mathrm{d} 1}=\frac{[\mathrm{H}][\mathrm{G}]}{[\mathrm{HG}]} \\
H G_{2} \leftrightarrow H G+G & K_{\mathrm{d} 2}=\frac{[\mathrm{HG}][\mathrm{G}]}{\left[\mathrm{HG}_{2}\right]}
\end{array}
$$

where $H$ is host, $G$ is guest, $H G$ and $H_{2}$ are the $1: 1$ complex and 1:2 complex, respectively, and square brackets denote equilibrium concentrations.

To obtain the dissociation constants from mass spectrometric titration data, it is useful to introduce host distribution coefficients $\alpha_{0}, \alpha_{1}$, and $\alpha_{2}$, incorporating suitable mass balance equations to relate equilibrium concentrations to initial concentrations used to set up the experiment. In this paper, we assume that mass spectral intensities of free host $\left(i_{\mathrm{H}}\right)$ and the 1:1 $\left(i_{\mathrm{HG}}\right)$ and 1:2 complexes $\left(i_{\mathrm{HG} 2}\right)$ truly reflect their solution concentrations and can therefore be used to determine the value of the distribution coefficients directly from mass spectra (rightmost terms in eqs 3a-3c). The goodness of fit of the gas-phase ion abundance data to the solution-phase binding model provides an indication of the correlation between the two.

$$
\begin{aligned}
& \alpha_{0}=\frac{[H]}{c_{0, H}}=\frac{[H]}{[H]+[H G]+\left[H G_{2}\right]}=\frac{i_{H}}{i_{H}+i_{H G}+i_{H G_{2}}} \\
& \alpha_{1}=\frac{[H G]}{c_{0, H}}=\frac{[H G]}{[H]+[H G]+\left[H G_{2}\right]}=\frac{i_{H G}}{i_{H}+i_{H G}+i_{H_{2}}} \\
& \alpha_{2}=\frac{\left[\mathrm{HG}_{2}\right]}{\mathrm{c}_{0, \mathrm{H}}}=\frac{\left[\mathrm{HG}_{2}\right]}{[\mathrm{H}]+[\mathrm{HG}]+\left[\mathrm{HG}_{2}\right]}=\frac{i_{\mathrm{HG}_{2}}}{i_{H}+i_{\mathrm{HG}}+i_{\mathrm{HG}_{2}}}
\end{aligned}
$$

With the knowledge of total concentrations of host $\left(\mathrm{c}_{0, \mathrm{H}}\right)$ and guest $\left(\mathrm{c}_{0, \mathrm{G}}\right)$ and the distribution coefficients read from spectra, it is possible to determine the equilibrium concentrations of $\mathrm{H}, \mathrm{HG}, \mathrm{HG}_{2}$ (eqs $3 \mathrm{a}-\mathrm{c}$ ) and, based on the mass balance equation of $G$ (eq 4), combined with eqs $3 a-c$, the guest equilibrium concentration (eq 5):

$$
\mathrm{c}_{0, \mathrm{G}}=[\mathrm{G}]+[\mathrm{HG}]+2\left[\mathrm{HG}_{2}\right]
$$

$$
[\mathrm{G}]=\mathrm{c}_{0, \mathrm{G}}-\mathrm{c}_{0, \mathrm{H}}\left(\alpha_{1}+2 \alpha_{2}\right)
$$

Therefore, it is at least theoretically possible to calculate the $K_{\mathrm{d}}$ values for any one-point measurement by substituting for equilibrium concentration in eq 1 and eq 2 from eqs $3 a-c$ and eq 5 :

$$
\begin{aligned}
& K_{\mathrm{d} 1}=\frac{\alpha_{0}}{\alpha_{1}\left[\mathrm{c}_{0, \mathrm{G}}-\mathrm{c}_{0, \mathrm{H}}\left(\alpha_{1}+2 \alpha_{2}\right)\right]} \\
& K_{\mathrm{d} 2}=\frac{\alpha_{1}}{\alpha_{2}\left[\mathrm{c}_{0, \mathrm{G}}-\mathrm{c}_{0, \mathrm{H}}\left(\alpha_{1}+2 \alpha_{2}\right)\right]}
\end{aligned}
$$

The result of titration experiments is a series of $\left(\alpha_{0}, \alpha_{1}\right.$, $\alpha_{2}$ ) sets corresponding to one data point for every combination of $c_{0, H}$ and $c_{0, G}$. Since it is preferable to obtain $K_{\mathrm{d}}$ values from the complete titration dataset rather then calculating a value for each titration point (and then taking their average, for example), we instead generate sets of distribution coefficients for different combinations of $K_{\mathrm{d} 1}$ and $K_{\mathrm{d} 2}$ and picked those dissociation constants that yielded sets as close to the experimental ones as possible. The dissociation degrees can be calculated by replacing the $\alpha_{0}$ in eq 7a with $1-\alpha_{1}-\alpha_{2}$ (since $\alpha_{0}+\alpha_{1}+\alpha_{2}=1$ ) and then solving eqs $6 \mathrm{a}$ and $6 \mathrm{~b}$ as a set of two equations with two unknowns $\left(\alpha_{1}, \alpha_{2}\right)$. Expressing $\alpha_{2}$ from eq $6 \mathrm{~b}$ and further substitution of $\alpha_{2}$ in eq $6 a$ yields a cubic expression (eq 7) that can be solved for $\alpha_{1}$ as it is the only unknown:

$$
\begin{aligned}
& {\left[\left(K_{\mathrm{d} 2}-4 K_{\mathrm{d} 1}\right) \mathrm{c}_{0, \mathrm{H}}^{2}\right] \alpha_{1}^{3}+\left(\mathrm{c}_{0, \mathrm{H}} K_{\mathrm{d} 2}^{2}-2 \mathrm{c}_{0, \mathrm{H}}^{2} K_{\mathrm{d} 2}\right.} \\
& \left.\quad-4 \mathrm{c}_{0, \mathrm{H}} K_{\mathrm{d} 1} K_{\mathrm{d} 2}\right) \alpha_{1}^{2}+\left(2 \mathrm{c}_{0, \mathrm{H}} \mathrm{c}_{0, \mathrm{G}} K_{\mathrm{d} 2}-\mathrm{c}_{0, \mathrm{G}} K_{\mathrm{d} 2}^{2}\right. \\
& \left.\quad-\mathrm{c}_{0, \mathrm{G}}^{2} K_{\mathrm{d} 2}-\mathrm{c}_{0, \mathrm{H}} K_{\mathrm{d} 2}^{2}-K_{\mathrm{d} 2}^{2} K_{\mathrm{d} 1}\right) \alpha_{1}+K_{\mathrm{d} 2}^{2} \mathrm{c}_{0, \mathrm{G}}=0
\end{aligned}
$$

To judge the degree of agreement between generated and experimental series of distribution coefficient sets, the sum of differences between generated $\left(\alpha_{0, \text { gen }}, \alpha_{1, \text { gen }}\right.$ $\left.\alpha_{2, \text { gen }}\right)$ and experimental $\left(\alpha_{0, \exp }, \alpha_{1, \exp }, \alpha_{2, \text { exp }}\right)$ values across all $N$ experimental points $(\Delta)$ is used. The sought pair of $K_{\mathrm{d} 1}, K_{\mathrm{d} 2}$ is determined by the minimal value of $\Delta$ associated with it.

$$
\begin{aligned}
\Delta=\sum_{\mathrm{i}=1}^{\mathrm{N}} & \left(\left|\alpha_{0, \text { gen }}-\alpha_{0, \exp }\right|+\mid \alpha_{1, \text { gen }}\right. \\
& \left.-\alpha_{1, \exp }|+| \alpha_{2, \text { gen }}-\alpha_{2, \exp } \mid\right)
\end{aligned}
$$

The $K_{\mathrm{d}}$ extraction from titration data for 1:1 binding is a simpler analogy of the procedure employed for 1:2 binding. Only one equilibrium is present in the system (eq 1) and therefore only two host distribution coefficients are introduced. As before, their values are obtained directly from the mass spectra:

$$
\alpha_{0}=\frac{[H]}{c_{0, H}}=\frac{[H]}{[H]+[H G]}=\frac{i_{H}}{i_{H}+i_{H G}}
$$




$$
\alpha_{1}=\frac{[H G]}{c_{0, H}}=\frac{[H G]}{[H]+[H G]}=\frac{i_{H G}}{i_{H}+i_{H G}}
$$

The analogous treatments for the mass balance of $G$ (eq 4) and the guest equilibrium concentration (eq 5) are reduced for 1:1 binding and incorporation of these expressions into eq 1 provides an expression for $K_{\mathrm{d}}$ in terms of host distribution coefficients and initial concentrations of host and guest:

$$
K_{\mathrm{d}}=\frac{\alpha_{0}}{\alpha_{1}\left(\mathrm{c}_{0, \mathrm{G}}-\mathrm{c}_{0, \mathrm{H}} \alpha_{1}\right)}
$$

The $\alpha_{0}$ in eq 10 can be replaced with $1-\alpha_{1}$ (since $\alpha_{0}+$ $\alpha_{1}=1$ ) and the equation can be then solved for $\alpha_{1}$ :

$$
\alpha_{1}=\frac{\mathrm{c}_{0, \mathrm{H}}+\mathrm{c}_{0, \mathrm{G}}+K_{\mathrm{d}}-\sqrt{\left(\mathrm{c}_{0, \mathrm{H}}+\mathrm{c}_{0, \mathrm{G}}+K_{\mathrm{d}}\right)^{2}-4 \mathrm{c}_{0, \mathrm{H}} \mathrm{c}_{0, \mathrm{G}}}}{2 \mathrm{c}_{0, \mathrm{H}}}
$$

Again, a series of $\left(\alpha_{0}, \alpha_{1}\right)$ sets were generated for different $K_{d}$ values. Using the criterion given in eq 12, a dissociation constant giving the distribution coefficients fitting best into the experimental data is chosen.

$$
\Delta=\sum_{\mathrm{i}=1}^{\mathrm{N}}\left(\left|\alpha_{0, \text { gen }}-\alpha_{0, \exp }\right|+\left|\alpha_{1, \text { gen }}-\alpha_{1, \exp }\right|\right)
$$

The experimental data for both 1:1 and 1:2 binding were processed with a computer program written in-house according to the equations and procedures described above using the Microsoft C\# 2005 Express Edition.

\section{Results and Discussion}

Cinchonane-type derivatives such as $\mathbf{1}$ have found widespread use as selective separation agents ("chiral selectors") for discriminating the enantiomers of chiral acids, specifically, N-blocked amino acids [21, 61, 63]. Virtually every mode of liquid-phase enantioselective separation has been investigated (except supercritical chromatography) and the interaction mechanism has been well characterized [62, 67, 68]. The protonated tertiary amine on the quinuclidine group of the host selector induces Coulombic attraction with the deprotonated carboxylate group on the guest enantiomer. Simultaneously, multiple contact sites through hydrogen bonding, $\pi-\pi$, and van der Waals interactions are induced to provide a high degree of stereoselectivity in binding to the guest enantiomers. The competition by achiral anions (acetate) in the mobile phase provides a crucial component to the enantioselective ion-exchange chromatographic separation mechanism. A strict 1:1 interaction between host and guest (e.g., 1 and 3 ) has been shown previously by NMR and isothermal titration calorimetry experiments [using slightly different guest enantiomers of 3,5-dinitrobenzoyl-leucine (DNBLeu)] [67].
This interaction system has been exploited with an aim of developing high throughput screening methods based on ESI-MS titration measurements in previous work $[25,26]$. Thus, the study of multivalency effects in the cinchonane-type chiral selector systems were pursued to investigate (1) whether tethering guest enantiomers to create bivalent forms would show increased retention and enantioselectivity in "chiral HPLC" (indicating the use of stationary phases to which is bound the chiral selector $\mathbf{1}$ for the purpose of differential retention of guest enantiomers), in a similar manner to that reported by Pirkle and coworkers [22, 23]; and (2) if mass spectrometric methods can offer complementary information in terms of interaction affinity, selectivity, and energetics of enantioselective multivalent chiral recognition systems.

Initial experiments by chiral HPLC were performed by comparing the retention and selectivity for enantiomers of monovalent 3 and bivalent $4 \mathrm{~N}$-blocked chiral acids. An initial separation of the enantiomers of $\mathbf{3}$ on a tBuCQN (1)-based CSP in polar organic mode returned capacity factors of $\mathrm{k}_{R}^{\prime}=1.19$ and $\mathrm{k}_{S}^{\prime}=7.66\left(\alpha_{\mathrm{HPLC}}=\right.$ $\mathrm{k}_{S}^{\prime} / \mathrm{k}_{R}^{\prime}=6.4, \Delta \Delta \mathrm{G}=4.61 \mathrm{~kJ} / \mathrm{mol}$ ). A representative chromatogram is shown in Figure 2a. When the enantiomers of the bivalent guest 4 were separated under identical conditions on the same CSP, values of $\mathrm{k}_{R, R}^{\prime}=$ 7.72 and $\mathrm{k}_{S, S}^{\prime}=312.20\left(\alpha_{\mathrm{HPLC}}=\mathrm{k}_{S, S}^{\prime} / \mathrm{k}_{R, R}^{\prime}=40.7, \Delta \Delta \mathrm{G}=\right.$
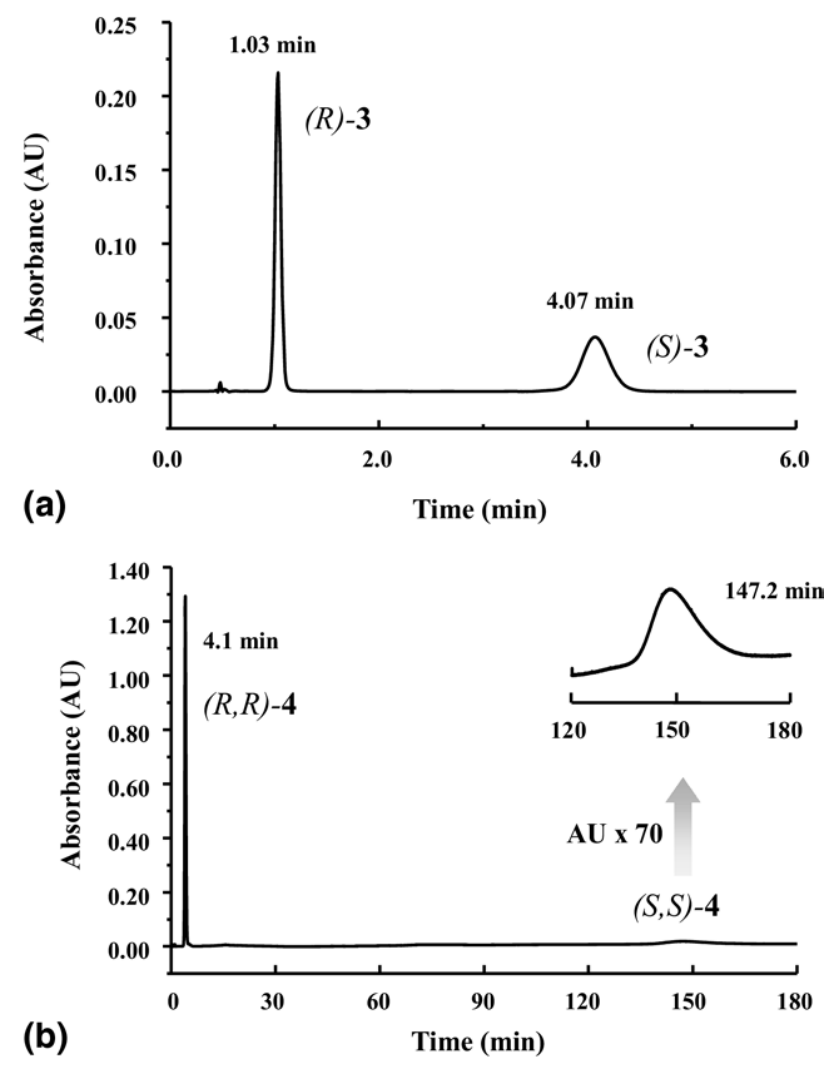

Figure 2. HPLC separation of enantiomers of monovalent 3 (a) and bivalent 4 (b) on a cinchonane-type CSP based from chiral selector 1 . 
$9.18 \mathrm{~kJ} / \mathrm{mol}$ ) were measured. A representative chromatogram is shown in Figure $2 b$. These results indicate that the bivalent receptor with a $\mathrm{C}_{6}$ tether unit possesses the ability to interact with multiple selector sites on the CSP surface simultaneously, thus increasing interaction affinity by a factor of two, and enantioselectivity more than 5-fold. The data successfully demonstrate the concept first illustrated by Pirkle and coworkers, a technique that was used originally to study the distance between selector sites on CSPs [22, 23].

To test the multivalency effect in mass spectrometric and tandem mass spectrometric experiments, the host molecules 1 and $\mathbf{2}$ and the guest molecules $\mathbf{3}$ and $\mathbf{4}$ (all enantiomer forms) were synthesized and purified using $\mathrm{C}_{6}$ tether units in $\mathbf{2}$ and $\mathbf{4}$ to allow appropriate and consistent spacing for concerted interactions in solution. Initial screening experiments, performed by simply mixing host and guest in suitable concentrations and represented by the spectra in Figure 3, showed responses of expected ion forms for the monovalent $(\mathbf{1}+$ 3 , Figure 3a), bivalent $(2+4$, Figure $3 b)$, and multiple monovalent $(2+3$, Figure $3 c)$ interaction systems. For the monovalent interaction case, the predominant ions observed were identified as protonated host and protonated host-guest complex. For the bivalent system, the mass spectrum is dominated by protonated and doubly-protonated host ion responses, as well as protonated and doubly protonated host-guest complex ions. For the multiple monovalent interaction system, similar and consistent ion forms were also observed. A response for the 1:2 (H:G) ionic complex can be detected, albeit in lower abundance compared to the 1:1 ionic complex, as seen in Figure $3 b$. Higher guest concentrations (up to $200 \mu \mathrm{M}$ ) were used to titrate the $1: 2$ interaction equilibria.

To test the quantitative nature of the interaction (through the measurement of concentration independent $K_{\mathrm{d}}$ values) and the correlation between gas-phase ion abundances and solution-phase equilibrium concentrations (by fitting the mass spectral data to a solution-phase-based interaction model), a series of MS-based titration experiments were performed whereby a series of mixtures comprising different host and guest concentrations were successively flowinjected through the ESI source. Figure 4 shows the fit of the mass spectral data $\left[\mathrm{I}=i_{\mathrm{H}} / i_{\mathrm{HG}}\right.$; based on the summed ion intensities of all signals related to the host $\left(i_{\mathrm{H}}\right)$ divided by the summed ion intensities of signals related to the host-guest complex $\left.\left(i_{\mathrm{HG}}\right)\right]$, plotted against initial guest concentration $\left(c_{0, G}\right)$, to the derived model for 1:1 interaction stoichiometry for the monovalent and bivalent interaction systems.

The fit of the data to the theoretical solution-phase model indicates that the gas-phase ion abundances correlate reasonably well with solution-phase concentrations. Points at low concentration, which give rise to a large $i_{\mathrm{H}} / i_{\mathrm{HG}}$ (between 100 and 1000) may be subject to increased uncertainty due the relative ion abundances incorporated and, thus, the use of low concentration points were restricted to those that could be recorded with $<50 \%$ relative standard error (RSE). With $i_{\mathrm{H}} /$ $i_{\mathrm{HG}}<500$, points were recorded with good precision ( $<15 \%$ RSE). Similarly, points at high concentration begin to deviate as the limit of linearity of the ESI process is approached. Error bars for standard error in each data point in Figure 4 are presented for $N=9$ (three replicates of three pseudo-replicates; see the Experimental section). Overall, data are presented and evaluated over the widest range of concentrations possible to judge the position of the equilibria in the most comprehensive manner.

The use of ESI-MS titrations as a tool to study solution-phase binding affinity in a quantitative manner is still a maturing art. Although specificity, sensitivity, and speed of analysis are strong advantages, it is prudent to discuss some of the limitations of the method. Previously, it was explained that association degree can be calculated directly from gas-phase ion abundances when we assume they are directly proportional to the solution-phase concentration (eqs $3 a-c$, $9 a-b)$. This is a safe assumption when working in the linear response regime of the ESI source (typically, $<50$ $\mu \mathrm{M})$. In the linear response range, the gas-phase ion abundance of each species is correlated with its equilibrium solution-phase concentration by a correlation coefficient, or response factor (i.e., $i_{\mathrm{X}}=f_{\mathrm{X}}[\mathrm{X}]$, where $f_{\mathrm{X}}$ denotes the response factor of any species $X$ at equilibrium concentration $[\mathrm{X}]$ ). In principle, it is impossible to deduce the equilibrium concentration of a resultant complex without first knowing the binding constant. Without knowing the equilibrium concentration, it is not possible to deduce an accurate response factor for the complex. This problem is similarly inherent to other spectroscopic titration techniques as well [69]. In ESI-MS titration experiments, it is commonly assumed that the response factor of the complex is approximately equivalent to the response factor of the free host (the guest response is not followed in this treatment). This assumption is most valid for situations (1) where the free host and host-guest complex(es) are similar in size, and (2) where the free host and the host-guest complex display identical charge states in the mass spectrum. When these assumptions are fulfilled, the physicochemical character of free host and host-guest complex ions would be similar, and be expected to give rise to similar ion response.

In this study, we deal with small molecule monovalent and bivalent diastereomeric complexes. Clearly systematic error in determined binding constants for these systems may be present due to the virtual doubling of size of the host-guest complex compared with the free host. In contrast, however, the results should be comparable on a relative basis. The charge states for the free host and the host-guest complex are preserved. Also, because the binding of enantiomers to a particular host are considered, the relative ionization efficiency of the diastereomeric complexes incorporating the different enantiomers should be similar (i.e., this is a best case 

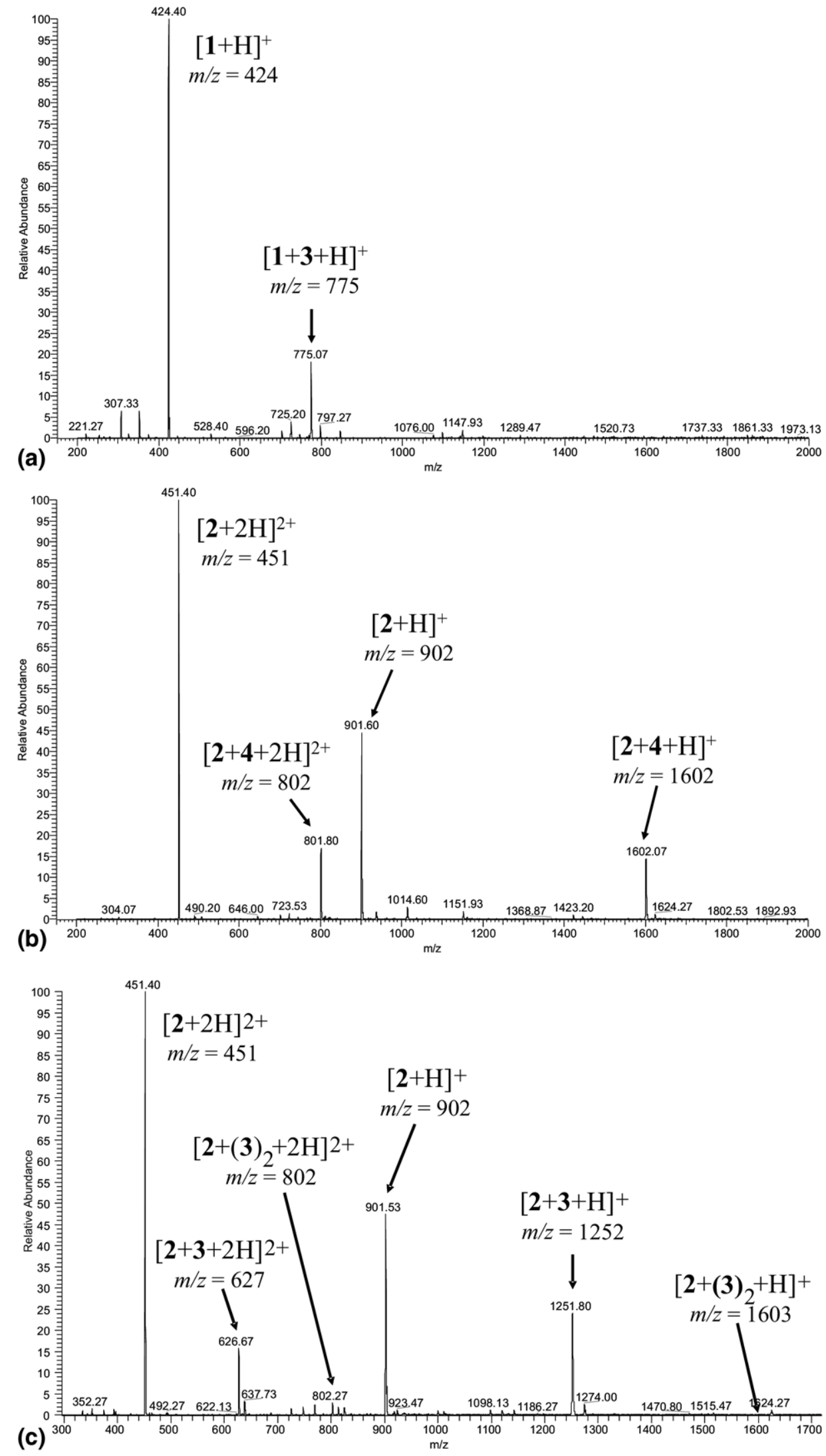

Figure 3. Representative mass spectra obtained through screening experiments (10 $\mu \mathrm{M}$ each of host and guest) for monovalent (a), bivalent (b), and multiple monovalent (c) interaction systems. Assigned major ion signals of interest are labeled. 

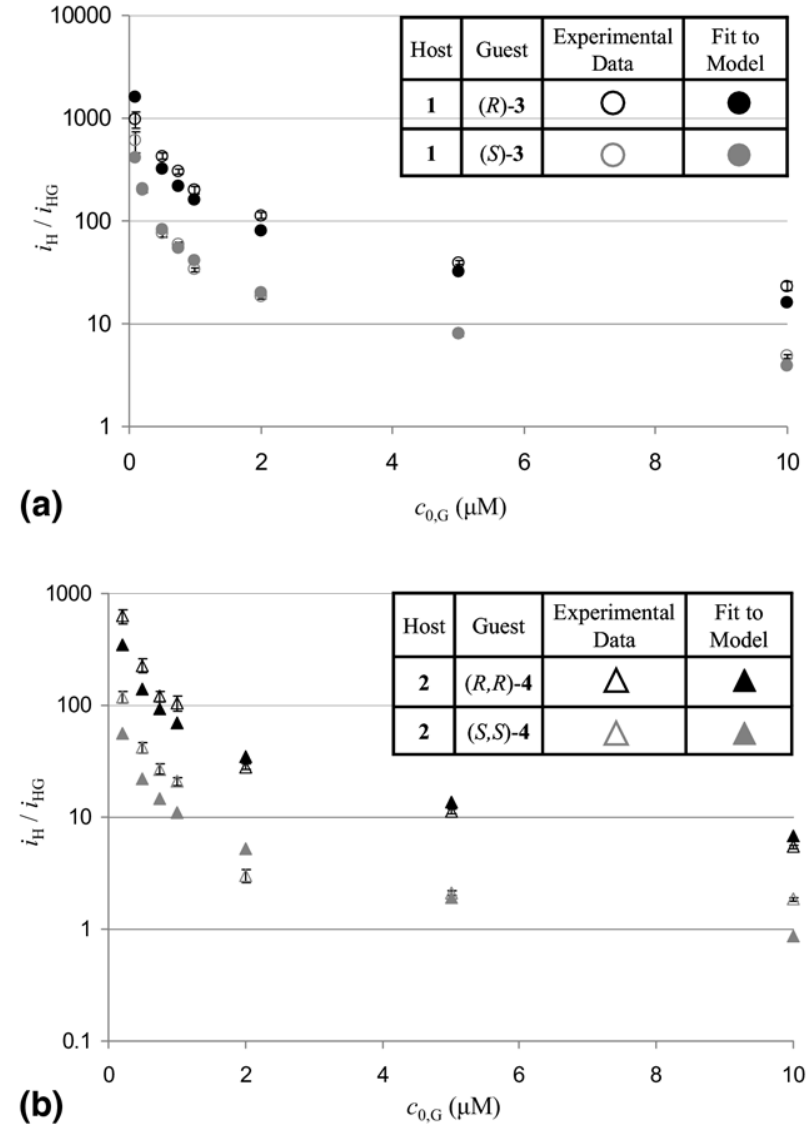

Figure 4. Mass spectrometric-based titration experimental data for monovalent (a) and bivalent (b) interaction systems. Error bars on experimental data represent standard error $(n=9)$ for each point.

scenario for studying small molecule binding by ESIMS). In comparing the monovalent and bivalent interaction systems, it is reasonable to assume that the relative response factors of the free host and the hostguest complexes are preserved because of the consistent structural make-up, giving rise to similar systematic error in each case. Because all responses for complexes are normalized to that of the free host in the applied model, the relative binding constants for the monovalent versus the bivalent systems should be comparable, and the results support this estimate.

Table 1 shows the results of the titration experiments. A 2- to 3-fold enhancement in binding affinity for the bivalent interaction system, compared with that for the monovalent case, is measured, in good agreement with that observed by HPLC. The RSE of the dissociation constants, determined from the average of three replicate measurements are acceptable, ranging from $\sim 5 \%$ to $25 \%$ across the different interaction systems investigated. The uncertainties in the $K_{\mathrm{d}}$ values are propagated to provide the uncertainties in the resultant mass spectrometry-based selectivity values. The enantioselectivity value for the monovalent case $\left(\alpha_{\mathrm{MS}}=\right.$ $K_{\mathrm{d}, \mathrm{R}} / K_{\mathrm{d}, \mathrm{S}}=6.1$ ) is similar in magnitude (ab initio) to that obtained by HPLC $\left(\alpha_{\text {HPLC }}=6.4\right)$; and the configu- rational preference is maintained (i.e., the enantiomer in the (S)-configuration binds more strongly to chiral selector 1). The enantioselectivity in the bivalent case is much lower for the mass spectrometry-based measurement $\left(\alpha_{\mathrm{MS}}=10\right)$ compared with HPLC $\left(\alpha_{\mathrm{HPLC}}=40.7\right)$; however, this may be explained by the mechanistic differences in the separation processes, as described previously. More importantly, the mass spectrometry analysis provides a consistent result for the increased avidity of the enantioselective bivalent interaction system, and the configurational preferences are maintained.

Evaluating the multiple monovalent interaction system $(2+3)$, key findings include (1) the binding affinity of the first $\left(K_{\mathrm{d} 1}\right)$ and second $\left(K_{\mathrm{d} 2}\right)$ association events are diminished relative to the monovalent $(1+3)$ interaction systems; (2) the corresponding selectivity $\left(\alpha_{\mathrm{MS}}=\right.$ 2.1) for the first binding event is also decreased in comparison to the monovalent system $\left(\alpha_{\mathrm{MS}}=6.1\right)$, but the expected configurational preference is maintained; (3) the binding affinity of the second association event $\left(K_{\mathrm{d} 2}\right)$ is similar in magnitude to the first association event $\left(K_{\mathrm{d} 1}\right)$ for the multiple monovalent system, indicating the approximate equivalence and independence of the two association events under these solution conditions; and (4) the selectivity of the second binding event $\left(\alpha_{\mathrm{MS}}=1.9\right)$ is very close to that for the first binding event $\left(\alpha_{\mathrm{MS}}=2.1\right)$ in the multiple monovalent interaction system. The latter points, (3) and (4) above, are consistent with expected results for a well behaved multiple monovalent interaction system. The discrepancies described in the former points, (1) and (2), are most likely due to systematic errors that can be ascribed to the relative response factor variation. In other words, the measurements for the multiple monovalent system are of interest to show the equivalence of binding sites, but the magnitude of the dissociation constants are probably not comparable to that for the monovalent and bivalent systems. The relative responses of free host and host-guest complex in the multiple monovalent systems are less likely to conform to that for the monovalent and bivalent interaction systems. In other words, it is assumed that $f_{\mathrm{H}} / f_{\mathrm{HG}}$ (monovalent) $\approx f_{\mathrm{H}} / f_{\mathrm{HG}}$ (bivalent) $\neq f_{\mathrm{H}} / f_{\mathrm{HG}}$ (multiple monovalent), because for

Table 1. Experimental results for mass spectrometric-based titration experiments investigating monovalent $(1+3)$, bivalent $(2+4)$, and multiple monovalent $(2+3)$ interaction systems

\begin{tabular}{clrcl}
\hline Host & Guest & $\begin{array}{c}K_{\mathrm{d} 1} \pm \mathrm{SE} \\
(\mu \mathrm{M})^{\mathrm{a}}\end{array}$ & $\begin{array}{c}K_{\mathrm{d} 2} \pm \mathrm{SE} \\
(\mu \mathrm{M})^{\mathrm{a}}\end{array}$ & $\alpha_{\mathrm{MS}}\left(=K_{\mathrm{d}, R} / K_{\mathrm{d}, S}\right)^{\mathrm{b}}$ \\
\hline \hline $\mathbf{1}$ & $(R)-3$ & $170 \pm 9$ & - & $6.1 \pm 0.4$ \\
& $(S)-3$ & $28 \pm 1$ & - & \\
2 & $(R, R)-4$ & $63 \pm 2$ & - & $10 \pm 3$ \\
& $(S, S)-4$ & $6 \pm 2$ & - & \\
2 & $(R)-3$ & $230 \pm 50$ & $220 \pm 30$ & $2.1 \pm 0.6,1.9 \pm 0.7^{\mathrm{c}}$ \\
& $(S)-3$ & $110 \pm 20$ & $110 \pm 30$ & \\
\hline
\end{tabular}

${ }^{\text {aAverage }}(n=3) \pm$ standard error

bUncertainty given based on propagation of error from $K_{\mathrm{d}, R} / K_{\mathrm{d}, S}$.

${ }^{\mathrm{c}} \alpha_{\mathrm{MS}}$ value based on $K_{\mathrm{d} 1}, K_{\mathrm{d} 2}$ from multiple monovalent interaction system. 
the monovalent and bivalent systems, a correspondingly similar increment of guest is added to the host in each case to form the complex. In contrast, for the multiple monovalent case, especially where bivalent host binds to monovalent guest $\left(K_{\mathrm{d}, 1}\right)$, the structure and, thus, the physicochemical characteristics of the resulting complex are not changed in a regular increment compared with the monovalent and bivalent systems. This speculative reasoning highlights the problem of comparing dissociation constants for interaction systems that may exhibit significant relative response differences when analyzed by ESI-MS titration experiments. Relative $K_{\mathrm{d}}$ values (selectivity) are of use to assess enantioselective performance (especially for monovalent systems), but absolute $K_{\mathrm{d}}$ values still need to be rigorously compared with values taken by complementary solution-phase methods.

By virtue of transferring the noncovalent diastereomeric complexes into the gas phase via ESI, and the use of an ion trap mass analyzer, relative binding affinities can also be investigated through gas-phase collision threshold measurements to obtain useful information in the absence of solvation $[65,66]$. Figure 5 shows this experimental determination for the monovalent $(\mathbf{1}+\mathbf{3})$ and the bivalent $(2+4)$ interaction systems. Table 2 gives the activation voltage necessary in each case to dissociate $50 \%$ of the parent ion complex $\left(\mathrm{V}_{50}\right)$, a measure of their relative stability. For both the monovalent and bivalent systems, unimolecular decomposition of the protonated 1:1 host-guest complex giving the free protonated host is consistently observed (neutral loss of guest is assumed) through the range of activation voltages investigated.

First, it is notable that enantioselectivity is significantly (if not completely) diminished in the gas phase relative to the solution phase for both the monovalent and bivalent interaction systems. Previous work has emphasized the delicate balance of noncovalent forces that give rise to enantioselectivity in these systems in

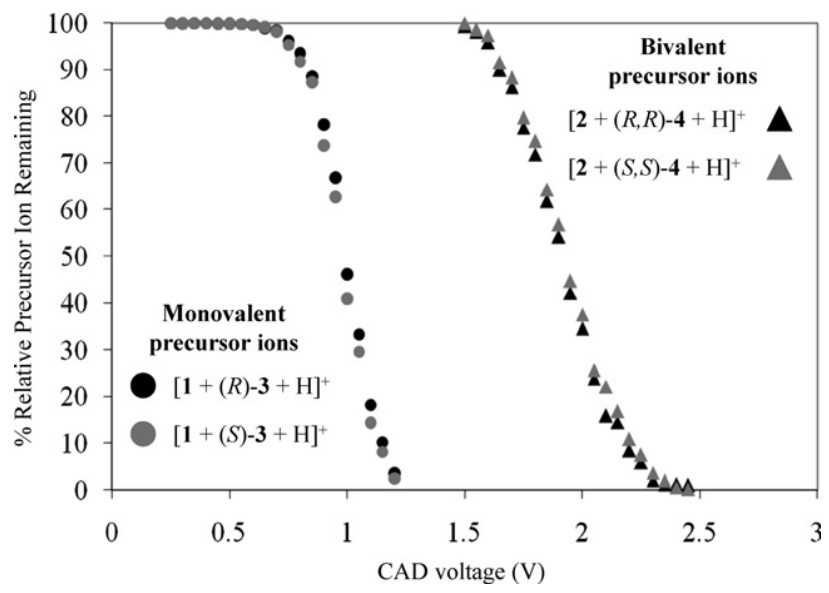

Figure 5. Experimental data for determination of collision threshold dissociation values for monovalent and bivalent singlycharged ionic complexes.
Table 2. Experimental determination of collision threshold dissociation values $\left(\mathrm{V}_{50}, n=3\right)$ for monovalent and bivalent interaction systems ${ }^{\mathrm{a}}$

\begin{tabular}{cllcc}
\hline Host & Guest & Isolated complex & $\mathrm{V}_{50}(\mathrm{~V})$ & $\begin{array}{c}\text { Corrected } \\
\mathrm{V}_{50}(\mathrm{~V})^{\mathrm{a}}\end{array}$ \\
\hline \hline $\mathbf{1}$ & $(R)-\mathbf{3}$ & {$[\mathbf{1}+(R)-\mathbf{3}+\mathrm{H}]+$} & $0.994 \pm 0.003$ & 0.994 \\
$\mathbf{1}$ & $(S)-\mathbf{3}$ & {$[\mathbf{1}+(S)-\mathbf{3}+\mathrm{H}]+$} & $0.982 \pm 0.002$ & 0.982 \\
$\mathbf{2}$ & $(R, R)-\mathbf{4}$ & {$[\mathbf{2}+(R, R)-\mathbf{4}+\mathrm{H}]+$} & $1.916 \pm 0.003$ & 0.919 \\
$\mathbf{2}$ & $(S, S)-\mathbf{4}$ & {$[\mathbf{2}+(S, S)-\mathbf{4}+\mathrm{H}]+$} & $1.931 \pm 0.007$ & 0.929 \\
\hline
\end{tabular}

a Average $\mathrm{V}_{50}$ value corrected based on RRKM arguments. Values for bivalent system are normalized by a factor (0.48) derived from the relative degrees of freedom in the monovalent (351) system to that for the bivalent (729) system.

the solution phase. An ion-exchange mechanism best describes the role of competing (achiral) anions in the solution phase that give rise to enantioselective interactions for these chiral selector systems [61, 67, 68]. Complexes stripped of solvent molecules tend to overexpress electrostatic binding increments because of the reduced dielectric of the gas-phase medium and, thus, distort the solvent-based enantioselective effects to reveal a different picture. Lacking a suitable ion-exchange competitor for binding, both the monovalent and bivalent chiral selectors lack appreciable enantioselective capacity for differentiating the binding of complementary analyte enantiomers in the gas phase.

Even more interesting is to compare the measured $\mathrm{V}_{50}$ values between the monovalent and bivalent interaction systems. It may be reasonable to conclude that the increased (approximately doubled) activation voltage necessary to dissociate the bivalent system translates to a concomitant increase in interaction affinity in the gas phase relative to the monovalent system. However, RRKM effects should be considered. The $V_{50}$ values measured by collisional activation in an ion trap are subjected to entropic contributions based on the larger number of degrees of freedom in the bivalent system composed from a larger number of atoms. The unimolecular decay of the bivalent system will be slower. Using simple RRKM arguments, the last column in Table 2 gives a corrected average $V_{50}$ value for the bivalent system, taking into account the entropic contributions to dissociation by normalizing the measured $\mathrm{V}_{50}$ value by a factor of 0.48 [the ratio of degrees of freedom in the monovalent system $(3 n-6=351 ; n=$ 119 atoms) to that for the bivalent system $(3 n-6=729 ; n=$ 245 atoms)]. This normalization puts the corrected $V_{50}$ values for the bivalent system in similar magnitude to but slightly lower than the monovalent system.

If we assume that RRKM effects are significant, this is an interesting finding in terms of investigating multivalent interaction systems by tandem mass spectrometry. In the work described previously by Huskens et al. [3], an intricate mathematical model is described to compare multivalent interactions indirectly based on dissociation constants (similar to the titration measurements discussed above). In contrast, the measurement of relative collisional activation voltages in tandem 
mass spectrometry may allow the direct measurement of relative interaction affinity at the level of dissociation energies. Although obtaining ab initio absolute energy values from collisional dissociation experiments in an ion trap is substantially (if not impossibly) complicated by the multicollision environment present, the fact that similar values for dissociation energies (based on corrected relative $V_{50}$ values) are obtained in these systems is not surprising. The systems investigated in this work are designed so that the bivalent system has twice the mass (and chemical bond repertoire) of the monovalent system. By applying the normalization procedure to the bivalent system, it is shown that the measurements provide the average dissociation energy of the underlying monovalent system directly and efficiently.

Whether RRKM are significant in this analysis remains to be comprehensively elucidated. While it is true that the bivalent complex will decay more slowly than the similarly-activated monovalent complex based on its greater number of degrees of freedom, this difference will affect the observed threshold only if the observation period is short compared with the decay time, or if ion cooling rates are of similar magnitude to decay rates. In a quadrupole ion trap, the observation period is relatively long. Additionally, under activation conditions, collisions should generally be activating rather than deactivating, and radiative cooling rates should be slow relative to the time scale of the experiment in an ion trap. Thus, it is still reasonable to suggest that the observed difference in dissociation threshold measured for the monovalent versus the bivalent system is mainly due to real energetic differences. Further experiments are underway to more comprehensively investigate the role of RRKM effects in the collisional dissociation of these systems.

\section{Conclusions}

Quantitative characterization of interaction strengths for multivalent (bivalent) enantioselective interaction systems using ESI-MS solution-phase- and MS/MS gas-phase-based methods have been demonstrated for the first time. The results indicate the viability of these methods in terms of studying multivalent recognition and that they can add new insight into the solventmediated enantioselective performance of cinchonanebased chiral selectors. It is concluded that mass spectrometry is an attractive tool in this regard, allowing the ability to monitor each component in the equilibria of interest. However, the inherent mechanistic differences that give rise to the enantioselectivity values in MS and HPLC measurements are amplified in light of the multivalent interaction systems. Whereas in previous studies and here, for the monovalent interaction systems, a suitable empirical correlation between the two techniques has been observed, mass spectrometrybased solution-phase titration experiments cannot adequately account for the vastly enhanced enantioselectivities obtained for bivalent systems by HPLC. In this regard, consideration of effective concentrations for multivalent surface-based enantioselective equilibria should be the focus of further experimentation aimed to reveal a more complete thermodynamic picture.

Evaluation of solution-phase binding affinity by ESI-MS titrations is a maturing art, providing accurate results in a system dependent manner. In this work, relative binding affinities are assumed comparable by virtue of (1) the similarity of the diastereomeric complexes being investigated, (2) the careful design of comparable monovalent versus bivalent interaction systems, and (3) the procedure by which complex ion responses are normalized to that of the respective free host ion. Still, the inability to determine response factors for the complexes induces systematic error that makes it more difficult to assess the accuracy of the absolute dissociation constant values. The study of multiple monovalent interactions in this light is especially problematic. Even so, increased avidity for binding due to the relative binding constants is apparent, and configurational preferences are maintained.

The gas-phase dissociation experiments provide a different picture than that which is present in the solution phase. Enantioselectivity is lost in the gas phase due to strengthened electrostatic forces and the lack of suitable competitors for supporting an ionexchange-type mechanism. However, the comparison of collisional dissociation thresholds via ion trap tandem MS demonstrates a potentially efficient means to directly study relative interaction affinities of multivalent systems. Further work is still needed in this area to assess the general applicability and limits of precision for such measurements, but these preliminary studies are encouraging.

\section{Acknowledgments}

K.A.S., M.D.J., and P.F. are grateful for financial support in the form of start-up funds from the University of Texas at Arlington. A portion of this work was presented as a poster at the 55th ASMS Conference on Mass Spectrometry and Allied Topics (June, 2007) in Indianapolis, IN. The authors acknowledge the helpful discussion on various points of the manuscript during revision by Professor R. Graham Cooks, Professor Jennifer S. Brodbelt, Dr. Amina S. Woods, and the anonymous reviewers. The authors also acknowledge the Center for Nanostructured Materials (College of Science, UT-Arlington) for their role in obtaining the MS instrumentation employed in this work.

\section{References}

1. Mammen, M.; Choi, S.-K.; Whitesides, G. M. Polyvalent Interactions in Biological Systems: Implications for Design and Use of Multivalent Ligands and Inhibitors. Angew. Chem. Int. Ed. 1998, 37, 2754-2794.

2. Mulder, A.; Huskens, J.; Reinhoudt, D. N. Multivalency in Supramolecular Chemistry and Nanofabrication. Org. Biomol. Chem. 2004, 2, 3409-3424.

3. Huskens, J.; Mulder, A.; Auletta, T.; Nijhuis, C. A.; Ludden, M. J. W.; Reinhoudt, D. N. A Model for Describing the Thermodynamics of Multivalent Host-Guest Interactions at Interfaces. J. Am. Chem. Soc. 2004, 126, 6784-6797.

4. Rao, J.; Whitesides, G. M. Tight Binding of a Dimeric Vancomycin Derivative with Dimeric $L$-Lys-D-Ala-D-Ala. J. Am. Chem. Soc. 1997, 119, 10286-10290. 
5. Rao, J.; Lahiri, J.; Isaacs, L.; Weis, R. M.; Whitesides, G. M. A Trivalent System from Vancomycin. $D$-Ala- $D$-Ala with Higher Affinity Than Avidin·Biotin. Science 1998, 280, 708-711.

6. Rao, J.; Yan, L.; Xu, B.; Whitesides, G. M. Using Surface Plasmon Resonance to Study the Binding of Vancomycin and its Dimer to Self-Assembled Monolayers Presenting D-Ala-D-Ala. J. Am. Chem. Soc. 1999, 121, 2629-2630.

7. Nieto, M.; Perkins, H. R. Physicochemical Properties of Vancomycin and Iodovancomycin and Their Complexes with Diacetyl- $L$-lysyl- $D$ alanyl-D-alanine. Biochem. J. 1971, 123, 773-787.

8. Nieto, M.; Perkins, H. R. Modification of the Acyl-D-Alanyl-D-Alanine Terminus Affecting Complex-Formation with Vancomycin. Biochem. J. 1971, 123, 789-803

9. Breslow, R.; Chang, B. Cholesterol Recognition and Binding by Cyclodextrin Dimers. J. Am. Chem. Soc. 1996, 118, 8495-8496.

10. Fulton, D.A.; Cantrill, S. J.; Stoddart, J. F. Probing Polyvalency in Artificial Systems Exhibiting Molecular Recognition. J. Org. Chem. 2002, $67,7968-7981$

11. Badjic, J. D.; Cantrill, S. J.; Grubbs, R. H.; Guidry, E. N.; Orenes, R.; Stoddart, J. F. The Exclusivity of Multivalency in Dynamic Covalent Processes. Angew. Chem. Int. Ed. 2004, 43, 3273-3278.

12. Badjic, J. D.; Nelson, A.; Cantrill, S. J.; Turnbull, W. B.; Stoddart, J. F. Multivalency and Cooperativity in Supramolecular Chemistry. Acc. Chem. Res. 2005, 38, 723-732.

13. Badjic, J. D.; Ronconi, C. M.; Stoddart, J. F.; Balzani, V.; Silvi, S.; Credi, A. Operating Molecular Elevators. J. Am. Chem. Soc. 2006, 128, 14891499.

14. Ludden, M. J. W.; Reinhoudt, D. N.; Huskens, J. Molecular Printboards: Versatile Platforms for the Creation and Positioning of Supramolecular Assemblies and Materials. Chem. Soc. Rev. 2006, 35, 1122-1134.

15. Varki, A. Biological Roles of Oligosaccharides: All of the Theories are Correct. Glycobiology 1993, 3, 97-130.

16. Van Vliet, L. D.; Ellis, T.; Foley, P. J.; Liu, L.; Pfeffer, F. M.; Russell, R. A.; Warrener, R. N.; Hollfelder, F.; Waring, M. J. Molecular Recognition of DNA by Rigid [n]-Polynorbornane-Derived Bifunctional Intercalators: Synthesis and Evaluation of Their Binding Properties. J. Med. Chem. 2007, 50, 2326-2340

17. Edayathumangalam, R. S.; Weyermann, P.; Gottesfeld, J. M.; Dervan, P. B.; Luger, K. Molecular Recognition of the Nucleosomal "Supergroove." Proc. Natl. Acad. Sci. U.S.A. 2004, 101, 6864-6869.

18. Pickens, J. C.; Mitchell, D. D.; Liu, J.; Tan, X.; Zhang, Z.; Verlinde, C. L. M. J.; Hol, W. G. J.; Fan, E. Nonspanning Bivalent Ligands as Improved Surface Receptor Binding Inhibitors of the Cholera Toxin B Pentamer. Chem. Biol. 2004, 11, 1205-1215.

19. Ferguson, M. R.; Fan, X.; Mukherjee, M.; Luo, J.; Khan, R.; Ferreon, J. C.; Hilser, V. J.; Shope, R. E.; Fox, R. O. Directed Discovery of Bivalent Peptide Ligands to an SH3 Domain. Prot. Sci. 2004, 13, 626-632.

20. Loidl, G.; Groll, M.; Musiol, H.-J.; Huber, R.; Moroder, L. Bivalency as a Principle for Proteasome Inhibition. Proc. Natl. Acad. Sci. U.S.A. 1999, 96, 5418-5422.

21. Maier, N. M.; Franco, P.; Lindner, W. Separation of Enantiomers: Needs, Challenges, Perspectives. J. Chromatogr. A 2001, 906, 3-33.

22. Pirkle, W. H.; Pochapsky, T. C. Separation of the Stereoisomers of a Homologous Series of bis-Amides on Chiral Stationary Phases. Chromatographia 1988, 25, 652-654.

23. Pirkle, W. H.; Readnour, R. S. Chromatographic Approach to the Measurement of the Interstrand Distance for Some Chiral Bonded Phases. Anal. Chem. 1991, 63, 16-20.

24. Ling, F. H.; Lu, V.; Svec, F.; Fréchet, J. M. J. Effect of Multivalency on the Performance of Enantioselective Separation Media for Chiral HPLC Prepared by Linking Multiple Selectors to a Porous Polymer Support via Aliphatic Dendrons. J. Org. Chem. 2002, 67, 1993-2002.

25. Schug, K. A.; Fryčák, P.; Maier, N. M.; Lindner, W. Measurement of Solution-Phase Chiral Molecular Recognition in the Gas Phase Using Electrospray Ionization-Mass Spectrometry. Anal. Chem. 2005, 77, 36613671.

26. Fryčák, P.; Schug, K. A. On-Line Dynamic Titration: Determination of Dissociation Constants for Noncovalent Complexes Using Gaussian Concentration Profiles by Electrospray Ionization-Mass Spectrometry. Anal. Chem. 2007, 79, 5407-5413.

27. Schug, K. A. Solution-Phase Enantioselective Recognition and Discrimination by Electrospray Ionization-Mass Spectrometry: State-of-the-Art Methods and an Eye Towards Increased Throughput Measurements. Comb. Chem. High Throughput Screening 2007, 10, 301-316.

28. Fryčák, P.; Schug, K. A. Dynamic Titration: Determination of Dissociation Constants for Noncovalent Complexes in Multiplexed Format Using HPLC-ESI-MS. Anal. Chem. 2008, 80, 1385-1393.

29. Loo, J. A. Studying Noncovalent Protein Complexes by Electrospray Ionization Mass Spectrometry. Mass Spectrom. Rev. 1997, 16, 1-23.

30. Veenstra, T. D. Electrospray Ionization Mass Spectrometry in the Study of Biomolecular Noncovalent Interactions. Biophys. Chem. 1999, 79, 63-79.

31. Brodbelt, J. S. Probing Molecular Recognition by Mass Spectrometry. Int. J. Mass Spectrom. 2000, 200, 57-69.

32. Schalley, C. A. Molecular Recognition and Supramolecular Chemistry in the Gas Phase. Mass Spectrom. Rev. 2001, 20, 253-309.

33. Daniel, J. M.; Friess, S. D.; Rajagopalan, S.; Wendt, S.; Zenobi, R. Quantitative Determination of Noncovalent Binding Interactions Using Soft Ionization Mass Spectrometry. Int. J. Mass Spectrom. 2002, 216, 1-27.
34. Nesatyy, V. J. Mass Spectrometry Evaluation of the Solution and Gas-Phase Properties of Noncovalent Protein Complexes. Int. J. Mass Spectrom. 2002, 221, 147-161.

35. Heck, A. J. R.; van den Heuvel, R. H. H. Investigation of Intact Protein Complexes by Mass Spectrometry. Mass Spectrom. Rev. 2004, 23, 368 389.

36. Di Tullio, A.; Reale, S.; De Angelis, F. Molecular Recognition by Mass Spectrometry. J. Mass Spectrom. 2005, 40, 845-865.

37. Loo, J. A.; Holsworth, D. D.; Root-Bernstein, R. S. Use of Electrospray Mass Spectrometry to Probe Antisense Peptide Interactions. Biol. Mass Spectrom. 1994, 23, 6-12.

38. Wang, K.; Gokel, G. W. Correlation of Solution- and Gas-Phase Complexation Assessed by Electrospray Ionization Mass Spectrometry: Application to One-, Two-, and Three-Ring Macrocycles. J. Org. Chem. 1996, 61, 4693-4697.

39. Kempen, E. C.; Brodbelt, J. S. A Method for Determination of Binding Constants by Electrospray Ionization Mass Spectrometry. Anal. Chem. 2000, 72, 5411-5416.

40. Dotsikas, Y.; Loukas, Y. L. Efficient Determination and Evaluation of Model Cyclodextrin Complex Binding Constants by Electrospray Mass Spectrometry. J. Am. Soc. Mass Spectrom. 2003, 14, 1123-1129.

41. Wortmann, A.; Rossi, F.; Lelais, G.; Zenobi, R. Determination of Zinc to $\beta$-Peptide Binding Constants with Electrospray Ionization Mass Spectrometry. J. Mass Spectrom. 2005, 40, 777-784

42. Siebert, H.-C.; Lu, S.-Y.; Frank, M.; Kramer, J.; Wechselberger, R.; Joosten, J.; Andre, S.; Rittenhouse-Olson, K.; Roy, R.; von der Lieth, C.-W.; Kapstein, R.; Vliegenhart, J. F. G.; Heck, A. J. R.; Gabius, H.-J. Analysis of Protein-Carbohydrate Interaction at the Lower Size Limit of the Protein Part (15-Mer Peptide) by NMR Spectroscopy, Electrospray Ionization Mass Spectrometry, and Molecular Modeling. Biochemistry 2002, 41, 9707-9717.

43. Young, D.-S.; Hung, H.-Y.; Liu, L. K. An Easy and Rapid Method for Determination of Stability Constants by Electrospray Ionization Mass Spectrometry. Rapid Commun. Mass Spectrom. 1997, 11, 769-773.

44. Sinz, A.; Jin, A. J.; Zschörnig, O. Evaluation of the Metal Binding Properties of a Histidine-Rich Fusogenic Peptide by Electrospray Ionization Fourier Transform Ion Cyclotron Resonance Mass Spectrometry. J. Mass Spectrom. 2003, 38, 1150-1159.

45. Lim, H.-K.; Hsieh, Y. L.; Ganem, B.; Henion, J. Recognition of Cell-Wall Peptide Ligands by Vancomycin Group Antibiotics: Studies Using Ion Spray Mass Spectrometry. J. Mass Spectrom. 1995, 30, 708-714.

46. Jorgensen, T. J. D.; Roepstorff, P.; Heck, A. J. R. Direct Determination of Solution Binding Constants for Noncovalent Complexes Between Bacterial Cell Wall Analogues and Vancomycin Group Antibiotics by Electrospray Ionization Mass Spectrometry. Anal. Chem. 1998, 70, 44274432.

47. Seymour, J. L.; Turecek, F.; Malkov, A. V.; Kocovsky, P. Chiral Recognition in Solution and the Gas Phase. Experimental and Theoretical Studies of Aromatic D- and L-Amino Acid-Cu(II)-Chiragen Complexes. J. Mass Spectrom. 2004, 39, 1044-1052.

48. Arakawa, R.; Kobayashi, M.; Ama, T. Chiral Recognition in Association between Antimony Potassium Tartarate and Bis(L-Alaninate) Ethylenediamine Cobalt(III) Complexes Using Electrospray Ionization Mass Spectrometry. J. Am. Soc. Mass Spectrom. 2000, 11, 804-808.

49. Sawada, M.; Shizuma, M.; Takai, Y.; Yamada, H.; Kaneda, T.; Hanafusa T. Enantioselectivity in FAB Mass Spectrometry. J. Am. Chem. Soc. 1992, 114, 4405-4406

50. Sawada, M. Chiral Recognition Detected by Fast Atom Bombardment Mass Spectrometry. Mass Spectrom. Rev. 1997, 16, 73-90.

51. Liang, Y.; Bradshaw, J. S.; Izatt, R. M.; Pope, R. M.; Dearden, D. V. Analysis of Enantiomeric Excess Using Mass Spectrometry: Fast Atom Bombardment/Sector and Electrospray Ionization/Fourier Transform Mass Spectrometric Approaches. Int. J. Mass Spectrom. 1999, 185/186/187, 977-988.

52. Filippi, A.; Giardini, A.; Piccirillo, S.; Speranza, M. Gas-Phase Enantioselectivity. Int. J. Mass Spectrom. 2000, 198, 137-163.

53. Dearden, D. V.; Liang, Y.; Nicoll, J. B.; Kellersberger, K. A. Study of Gas-Phase Molecular Recognition Using Fourier Transform Ion Cyclotron Resonance Mass Spectrometry. J. Mass Spectrom. 2001, 36, 989-997.

54. Grigorean, G.; Gronert, S.; Lebrilla, C. B. Enantioselective Gas-Phase Ion/Molecule Reactions in a Quadrupole Ion Trap. Int. J. Mass Spectrom. 2002, 219, 79-87.

55. Grigorean, G.; Cong, X.; Lebrilla, C. B. Chiral Analysis of Peptides by Ion/Molecule Reactions. Int. J. Mass Spectrom. 2004, 234, 71-77.

56. Tao, W. A.; Cooks, R. G. Chiral Analysis by MS. Anal. Chem. 2003, 75, 25A-31A.

57. Speranza, M. Enantioselectivity in Gas-Phase Ion-Molecule Reactions. Int. J. Mass Spectrom. 2004, 232, 277-317.

58. Schug, K. A.; Lindner, W. Chiral Molecular Recognition for the Detection and Analysis of Enantiomers by Mass Spectrometric Methods. J. Sep. Sci. 2005, 28, 1932-1955.

59. Kitova, E. N.; Kitov, P. L.; Bundle, D. R.; Klassen, J. S. The Observation of Multivalent Complexes of Shiga-like Toxin with Globotriaoside and the Determination of their Stoichiometry by Nanoelectrospray FourierTransform Ion Cyclotron Resonance Mass Spectrometry. Glycobiology 2001, 11, 605-611.

60. Broeren, M. A. C.; van Dongen, J. L. J.; Pittelkow, M.; Christensen, J. B.; van Genderen, M. H. P.; Meijer, E. W. Multivalency in the Gas Phase: The Study of Dendritic Aggregates by Mass Spectrometry. Angew. Chem. Int. Ed. 2004, 43, 3557-3562. 
61. Lämmerhofer, M.; Lindner, W. Quinine and Quinidine Derivatives as Chiral Selectors. I. Brush Type Chiral Stationary Phases for High Performance Liquid Chromatography based on Cinchonan Carbamates and Their Application as Chiral Anion Exchangers. J. Chromatogr. A 1996, 741, 33-48.

62. Maier, N. M. Schefzick, S.; Lombardo, G. M. Feliz, M.; Rissanen, K. Lindner, W.; Lipkowitz, K. B. Elucidation of the Chiral Recognition Mechanism of Cinchona Alkaloid Carbamate-type Receptors for 3,5Mechanism of Cinchona Alkaloid Carbamate-type Receptors for 3,5-
Dinitrobenzoyl Amino Acids. J. Am. Chem. Soc. 2002, 124, 8611-8629.

63. Maier, N. M.; Nicoletti, L.; Lämmerhofer, M.; Lindner, W. Enantioselective Anion Exchangers Based on Cinchona Alkaloid-Derived Carbamates: Influence of C8/C9 Stereochemistry on Chiral Recognition. Chirality 1999, 11, 522-528.

64. Schug, K. A.; Lindner, W. Using Electrospray Ionization-Mass Spectrometry/Tandem Mass Spectrometry and Small Molecules to Study Guanidinium-Anion Interactions. Int. J. Mass Spectrom. 2005, 241, 11-23.

65. Wan, K. X.; Gross, M. L.; Shibue, T. Gas-Phase Stability of DoubleStranded Oligodeoxynucleotides and Their Noncovalent Complexes with DNA-Binding Drugs as Revealed by Collision Activation in an Ion Trap. J. Am. Soc. Mass Spectrom. 2000, 11, 450-457.

66. Colorado, A.; Brodbelt, J. An Empirical Approach to Estimation of Critical Energies by Using a Quadrupole Ion Trap. J. Am. Soc. Mass Spectrom. 1996, 7, 1116-1125.

67. Lah, J.; Maier, N. M.; Lindner, W.; Vesnaver, G. Thermodynamics of Binding of (R)- and (S)-Dinitrobenzoyl Leucine to Cinchona Alkaloids and their tert-Butylcarbamate Derivatives in Methanol: Evaluation of Enantioselectivity by Spectroscopic (CD, UV) and Microcalorimetric (ITC) Titrations. J. Phys. Chem. B 2001, 105, 1670-1678.

68. Czerwenka, C.; Zhang, M. M.; Kählig, H.; Maier, N. M.; Lipkowitz, K. B.; Lindner, W. Chiral Recognition of Peptide Enantiomers by Cinchona Alkaloid Chiral Selectors: Mechanistic Investigations by Liquid Chromatography, NMR Spectroscopy, and Molecular Modeling. J. Org. Chem. 2003, 68, 8315-8327.

69. Hirose, K. A Practical Guide to Determination of Binding Constants. J. Incl. Phenom. Macrocycl. Chem. 2001, 39, 193-209. 